\title{
"Querido diário..." A construção do conheci- mento histórico por meio dos quadrinhos de Anne Frank
}

\section{Resumo}

Bruna Mozini Subtil

Miriã Lúcia Luiz

Universidade Federal do Espírito Santo (Brasil)

Neste estudo, analisa-se as possibilidades de construção do saber histórico por meio das histórias em quadrinhos, especificamente, $O$ diário de Anne Frank em Quadrinhos, adaptado por Mirella Spinelli (2017). Fundamenta-se teoricamente nas noções de consciência histórica, de Jörn Rüsen (201 1), literacia e empatia histórica, de Peter Lee (2016; 2003) e metodologicamente, no pensamento de Marc Bloch (2001) e de Jörn Rüsen (2011). No âmbito do estudo, constrói-se uma proposta de ensino explorando a graphic novel, com o objetivo de favorecer a elaboração do conhecimento histórico pelos estudantes. Os resultados apontaram conceitos da História que poderão ser construídos por meio do uso da história em quadrinhos na sala de aula, como, tempo histórico, memória, cidadania, alteridade e fato histórico, o que permite mobilizar o conhecimento histórico como uma maneira de construir sentido e organizar, temporalmente, as experiências dos sujeitos, culminando numa História que tem por objetivo a formação da consciência histórica.

Palavras-chave: Ensino de história. História em quadrinhos. Consciência histórica. Literacia histórica.

\section{"Dear diary..." The construction of historical knowledge through Anne Frank comic books}

\begin{abstract}
In this study, the possibilities of building historical knowledge through comic books are analyzed, specifically, the Diary of Anne Frank in Comics, adapted by Mirella Spinelli (2017). It is theoretically based on the notions of historical awareness by Jörn Rüsen (2011) and historical literacy and empathy by Peter Lee (2016; 2003). Methodologically, it is anchored in the thinking of Marc Bloch (2001) and Jörn Rüsen (2011). Within the scope of the study, a teaching proposal is built exploring the graphic novel, with the aim of favoring the development of historical knowledge by students. The results pointed to concepts of History that can be constructed through the use of comic books in the classroom, such as historical time, memory, citizenship, alterity and historical fact, allowing the mobilization of historical knowledge as a way to build meaning and organize, temporally, the experiences of the subjects, culminating in a History whose objective is to raise historical awareness.
\end{abstract}


"Querido diário..." A construção do conhecimento histórico por meio dos quadrinhos de Anne Frank

Keywords: History Teaching. Comic book. Historical awareness. Historical literacy.

\section{"Querido diario..." La construcción del conocimiento histórico por medio de historietas de Anne Frank}

\section{Resumen}

En este estudio, se analiza las posibilidades de construcción del saber histórico por medio de los cómics, especificamente, El diário de Anne Frank en Historietas, adaptado por Mirella Spinelli (2017). Se fundamenta teoricamente en las nociones de conciencia histórica de Jörn Rüsen (2011) y literacia y empatia histórica, de Peter Lee (2016; 2003). Metodológicamente, se apoya en el pensamiento de Marc Bloch (2001) y de Jörn Rüsen (201 1). En el ámbito del estudio, se construye una propuesta de enseñanza explorando la graphic novel, con el objetivo de favorecer la elaboración del conocimiento histórico por los estudiantes. Los resultados apuntaron conceptos de la Historia que podrán ser construidos por medio del uso de las historietas en el salón de clases, como, tiempo histórico, memoria, ciudadanía, alteridad y hecho histórico, permitiendo movilizar el conocimiento histórico como una forma de construir sentido y organizar, temporalmente, las experiencias de los sujetos, culminando en una Historia que tiene por objetivo la formación de la conciencia histórica.

Palabras claves: Enseñanza de la historia. Historietas en cuadritos. Consciencia histórica. Literatura histórica.

\section{Introdução}

O número de obras referentes ao diálogo da História com a Literatura é de notável extensão, principalmente após a década de 1970 com a revolução documental da Escola dos Annales, em que o conceito de fonte histórica se amplia e se modifica radicalmente (PEREIRA; SEFFNER, 2008). Nesse sentido, devido ao fato de a historiografia especializada nessa esfera estar em evidente crescimento, delineamos um panorama da discussão historiográfica a respeito do diálogo entre essas duas disciplinas no ambiente escolar por meio das dissertações e teses publicadas.

Para o levantamento bibliográfico, acessamos os portais da Biblioteca Digital de Teses e Dissertações da Universidade de São Paulo (USP), do Repositório Institucional da Universidade Federal do Espírito Santo (UFES) e da Biblioteca Digital Brasileira de Teses e Dissertações (BDTD), com a finalidade de encontrar pesquisas que se aproximem da proposta de estudo. 
Em âmbito nacional, devemos destacar que, em comparação com a quantidade de pesquisas que utilizam a literatura como documentação principal, há significantemente menos estudos sobre a área de ensino de História que mobilize, como recurso didático ou fonte para serem utilizadas na sala de aula, as histórias em quadrinhos. Além disso, pudemos averiguar uma lacuna historiográfica existente no estado do Espírito Santo, tendo em vista que não encontramos estudos que se aproximem desta proposta de investigação nos portais da Universidade Federal do Espírito Santo no que se refere à História e Educação, mesmo que existam pesquisas que tangenciam esse tema em áreas afins, como a de Letras.

A partir da revisão bibliográfica, também averiguamos que existe uma tendência historiográfica de interpretação da literatura no ensino de História como prática didática, utilizando-a como um meio de complementar determinado contexto ou para exemplificar algum conteúdo histórico. Entretanto, visamos a uma abordagem diferente, pautada no pensamento rüseniano, que mobiliza conceitos "[...] estruturadores que estão submissos às operações mentais do pensamento histórico sem os quais é impossível desenvolver esse conhecimento e, consequentemente, sua aplicação na vida prática" (ALVES, 2011, p. 55).

Para tal, objetivamos, de forma geral, analisar as possibilidades de construção do conhecimento histórico por meio das histórias em quadrinhos, especificamente, $O$ diário de Anne Frank em Quadrinhos, adaptado por Mirella Spinelli (2017), mediando a elaboração de conceitos da História pelos estudantes, além de sugerir uma proposta de ensino capaz de identificar as possibilidades de formação da consciência histórica, a literacia e a empatia histórica nos estudantes. De forma específica, o artigo: a) mapeia os conceitos históricos da fonte literária; b) elenca as competências narrativas propostas por Rüsen (201 1); c) investiga os possíveis percursos das aprendizagens; e d) detalha os procedimentos, tendo em vista que esta é uma das maneiras de se trabalhar com as HQs em sala de aula.

Para tal, mobilizamos a graphic novel $O$ diário de Anne Frank em Quadrinhos, obra adaptada e ilustrada por Mirela Spinelli (2017), levando em consideração as lacunas historiográficas existentes nos estudos sobre as histórias em quadrinhos e também a ausência de dissertações e teses que dialoguem com o testemunho de Anne Frank no ensino de História, já que as pesquisas encontradas eram investigadas, majoritariamente, pelo campo do 
"Querido diário..." A construção do conhecimento histórico por meio dos quadrinhos de Anne Frank

saber das Letras e trabalhavam com a fonte escrita produzida por Anne Frank, mas não com sua graphic novel.

Para este estudo, analisamos a primeira edição da fonte literária selecionada, O diário de Anne Frank em Quadrinhos (SPINELLI, 2017), obra ilustrada e roteirizada por Mirella Spinelli e publicada em março de 2017, pela Nemo. Essa editora faz parte do Grupo Autêntica e seu catálogo é caracterizado, principalmente, por histórias em quadrinhos, dividindo-se em algumas áreas temáticas como "graphic novels", "adaptações", "quadrinhos estrangeiros", "quadrinhos nacionais", entre outros. Também devemos ressaltar que a obra selecionada faz parte do Programa Nacional do Livro e do Material Didático (PNLD) de 2020 , política que examina e viabiliza o acesso de maneira gratuita a materiais didáticos, literários e pedagógicos, buscando contribuir e apoiar a educação das escolas públicas de todas as esferas, não possuindo quaisquer fins lucrativos (BRASIL, 2021).

A história em quadrinhos do diário pessoal de Anne Frank possui noventa e seis páginas, acabamento em brochura e, na primeira página, informa que foi adaptada da obra, escrita pela adolescente, de título original: O Anexo: notas do diário de 12 de junho de 1942 a $1^{\circ}$ de agosto de 1944.

A princípio, um elemento paradoxal chamou-nos a atenção, pois na orelha do livro encontra-se a seguinte descrição: "Esta é uma adaptação em quadrinhos dos textos originais, sem cortes ou alterações, escritos por Anne Frank". No entanto, ao fazer o recorte do que seria mais importante de ser representado em cada dia do diário pessoal de Anne Frank, já que os relatos não foram escritos na íntegra, a roteirista e ilustradora, Mirella Spinelli, acaba por também inserir sua interpretação da obra.

Torna-se importante contextualizar o diário como fonte literária - formato que a obra adaptada para a HQ mantém - que, de acordo com Silva (2021, p. 15), compõe o gênero conhecido como "escritas de si" e, consequentemente, faz parte de uma literatura expressiva, sendo um vestígio histórico fundamental para os pesquisadores dessa área, já que permite conhecer "[...] os modos de se narrar de uma dada época, os registros de vida de um indivíduo e as experiências coletivas de uma dada sociedade, além dos sistemas simbólicos, econômicos, políticos e os códigos culturais de um período histórico". Não obstante, Silva (2021) destaca que a análise e o tratamento dos dados do diário devem ser cuidadosos, principalmente por conta das 
problemáticas envolvendo a memória histórica de natureza individual do período estudado.

Por tratar-se de uma história em quadrinhos, também é relevante ressaltar que essa documentação literária é pertinente por ser um gênero que as crianças já estão familiarizadas quando chegam à escola, além de ser um formato pedagogicamente interessante para os discentes e para sua formação como leitores, sendo uma maneira de introduzi-los à literatura (AMARILHA, 2009).

Dessa forma, para analisar a história em quadrinhos como recurso didático que possibilite a construção do conhecimento histórico, baseamo-nos, principalmente, nas reflexões de Jörn Rüsen (201 1) sobre a noção de consciência histórica e nos conceitos de literacia e empatia histórica, tal como propostos por Peter Lee $(2016,2003)$. Essa teorização nos respalda na interpretação da documentação e na construção da proposta de ensino que tem como objetivo principal a elaboração do pensamento histórico.

O aporte conceitual de Jörn Rüsen apresenta a consciência histórica como a parte teórica da aprendizagem histórica. Sendo assim, para o autor:

A consciência histórica pode ser descrita como a atividade mental da memória histórica, que tem sua representação em uma interpretação da experiência do passado encaminhada de maneira a compreender as atuais condições de vida e a desenvolver perspectivas de futuro na vida prática conforme a experiência [...]. Será algo que ocorre quando a informação inerte, progressivamente interiorizada, torna-se parte da ferramenta mental do sujeito e é utilizada, com alguma consciência, como orientação do quotidiano (RÜSEN, 2011 , p. 16 e 112 ).

Entendemos que trabalhar com o conhecimento histórico seria uma maneira de construir sentido e organizar, temporalmente, as experiências dos sujeitos, culminando numa História que tem por objetivo a formação da consciência histórica.

Essa concepção de consciência histórica de Rüsen foi essencial para o desenvolvimento de outro conceito: o da literacia histórica. Peter Lee (2006), justifica a abordagem de Rüsen como ponto de partida para suas reflexões, tendo em vista que é somente a partir de nossos interesses que podemos construir uma compreensão histórica que nos oriente na dimensão temporal. $\bigcirc$ autor 
"Querido diário..." A construção do conhecimento histórico por meio dos quadrinhos de Anne Frank

define a noção de literacia pela maneira de "compreender a história como uma forma de ver o mundo" e, para tal, os professores tem a função de desenvolver uma representação do passado que possibilite aos estudantes se orientar temporalmente e a perceber o passado como um fenômeno que impacta no presente (LEE, 2016, p. 121).

Além disso, para Peter Lee, um meio viável para que os estudantes possam ter uma melhor compreensão histórica seria pelo conceito de empatia histórica, definindo-o como:

[...] algo que acontece quando sabemos o que o agente histórico pensou, quais os seus objetivos, como entenderam aquela situação e se conectamos tudo isso com o que aqueles agentes fizeram (LEE, 2003, p. 20).

Sendo assim, Schmidt (2017) associa o conceito de consciência histórica de Rüsen e à noção de literacia histórica de Peter Lee, essa última sendo definida como uma maneira de pensar historicamente, transformando informação em conhecimento histórico. Dessa maneira, esse aporte teórico não busca o acúmulo de informações, mas a ensinar como o pensamento histórico pode 6 ser formulado pelos estudantes e, ao mesmo, tornar a consciência histórica mais complexa.

Já no referencial metodológico, amparamo-nos nos pressupostos de Bloch (2001) no que tange à pesquisa em perspectiva histórica e para a construção do questionário sociocultural. E, por fim, operacionalizamos a metodologia de Rüsen (201 1), sobre o material didático ideal, orientando-nos para os aspectos que uma proposta didática deve ter a fim de que os estudantes possam elaborar suas aprendizagens e, em última instância, formar a consciência histórica.

Nesse sentido, a recomendação de prática didática construída por meio da HQ é composta, inicialmente, pela elaboração de um questionário sociocultural, a partir da concepção de Bloch (2001) sobre a importância de investigar os conhecimentos prévios dos estudantes referente à temática e pela construção de duas sugestões de atividades. A primeira abordagem de ensino mobiliza os conceitos de Peter Lee $(2003 ; 2016)$, objetivando averiguar se os estudantes desenvolveram a literacia e a empatia histórica por meio de sua compreensão a respeito da fonte literária e do contexto histórico; enquanto a 
segunda atividade tem como finalidade perceber como os alunos interpretam os conceitos históricos e as fontes imagéticas.

Ambas as recomendações de práticas intencionam investigar a formação da consciência histórica, conceito formulado por Rüsen (201 1) em seu aporte teórico-metodológico. Sendo assim, estruturamos a proposta de ensino a partir das competências perceptivas, interpretativas e de orientação, elaboradas por Rüsen (201 1) ao pensar no material didático ideal para a constituição da consciência histórica pelos discentes.

Nesse sentido, no primeiro tópico deste artigo apresentamos o mapeamento dos conceitos históricos que compõem a proposta didática de uso das HQs, definindo o público a que se destina, os conteúdos que podem ser mobilizados e as noções históricas a serem elaboradas nas atividades. No tópico seguinte, sublinhamos os contornos de um questionário sociocultural, dialogando com o aporte teórico e metodológico de Bloch (2001). Para concluir, no terceiro tópico serão apresentadas duas propostas de ensino, detalhando os possíveis percursos de aprendizagem e os procedimentos a serem adotados para a realização da sugestão de ensino, por meio da teorização de Lee (2003; 2016) e Rüsen (2011).

\section{A construção de uma proposta de ensino a partir das histórias em quadrinhos e os conceitos históricos}

A obra literária selecionada trata de conteúdos que são contextualizados na Segunda Guerra Mundial, focalizando, de modo específico, o holocausto, judaísmo, a instituição dos regimes totalitários, fascismo, nazismo e as consequências da guerra; por isso, para uma abordagem pedagógica, a HQ O diário de Anne Frank em Quadrinhos (SPINELLI, 2017) tem como público-alvo os dois últimos anos do ensino fundamental II, especialmente o nono ano.

Ao direcionar-se, a priori, para o trabalho na disciplina de História, propomos uma abordagem de ensino em que, após uma análise prévia da documentação literária, a história em quadrinhos seja abordada como um recurso didático que possa ser usado no ambiente escolar, destacando os conceitos históricos mapeados a partir da obra $\bigcirc$ diário de Anne Frank em Quadrinhos (SPINELLI, 2017). 
Com efeito, optamos por explorar conteúdos que "[...] abordam conceitos, fatos, teorias, hipóteses e princípios e se referem à construção ativa e dinâmica das capacidades intelectuais para que os alunos possam operar símbolos, signos, ideias, imagens que representam a realidade" (AZEVEDO, 2013 , p. 17). Ou seja, objetivamos operar conceitos históricos os quais os estudantes possam aplicar também em outros contextos e não somente nas aulas de História.

Nesse sentido, selecionamos cinco noções históricas, identificadas na fonte literária, para serem exploradas na abordagem didática sugerida, quais sejam: tempo histórico, memória, alteridade, cidadania e fato histórico. Para

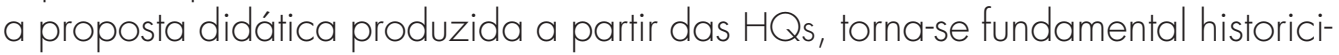
zar e apontar algumas construções conceituais, amparando-nos em referências como Bloch (2001), Halbwachs (2006) e Rüsen (2011).

Para o conceito de tempo histórico, baseamo-nos na compreensão de Marc Bloch (2001) de que a temporalidade não é somente um marco de durabilidade, já que nosso pensamento é uma característica do tempo em que vivemos. Sendo assim, o autor define a História como a ciência que pretende compreender os homens e mulheres no tempo, considerando que a temporalidade pode ser definida como "[...] realidade concreta e viva, submetida à irreversibilidade de seu impulso, o tempo da história, ao contrário, é o próprio plasma em que se engastam os fenômenos e como o lugar de sua inteligibilidade" (BLOCH, 200 1, p. 55).

Nesse movimento, a adaptação literária se guia por uma orientação cronológica, em que podemos perceber uma abordagem que mobiliza a percepção de tempo histórico, interligando a narrativa de Anne Frank sobre os conflitos da adolescência, com a História do cotidiano e com os momentos históricos da Segunda Guerra Mundial. Dessa forma, esse relato percorre a visão micro e macro da História ao interagir e dialogar com o contexto histórico e os registros rotineiros da adolescente, tornando esse formato interessante pedagogicamente para o ensino de História, de modo a possibilitar uma conexão dos estudantes da sua realidade com o tempo em que vivem.

A concepção de memória pode ser percebida pelo fragmento da obra literária em que os moradores do Anexo escutam em um rádio sobre a coletânea de diários e cartas que seria feita após o fim da Segunda Guerra 
Mundial e, a partir disso, Anne Frank cogita a possibilidade de publicar seus escritos, chegando a reescrevê-los e reorganizá-los depois deste anúncio:

\section{Figura 1: Conceito de memória}
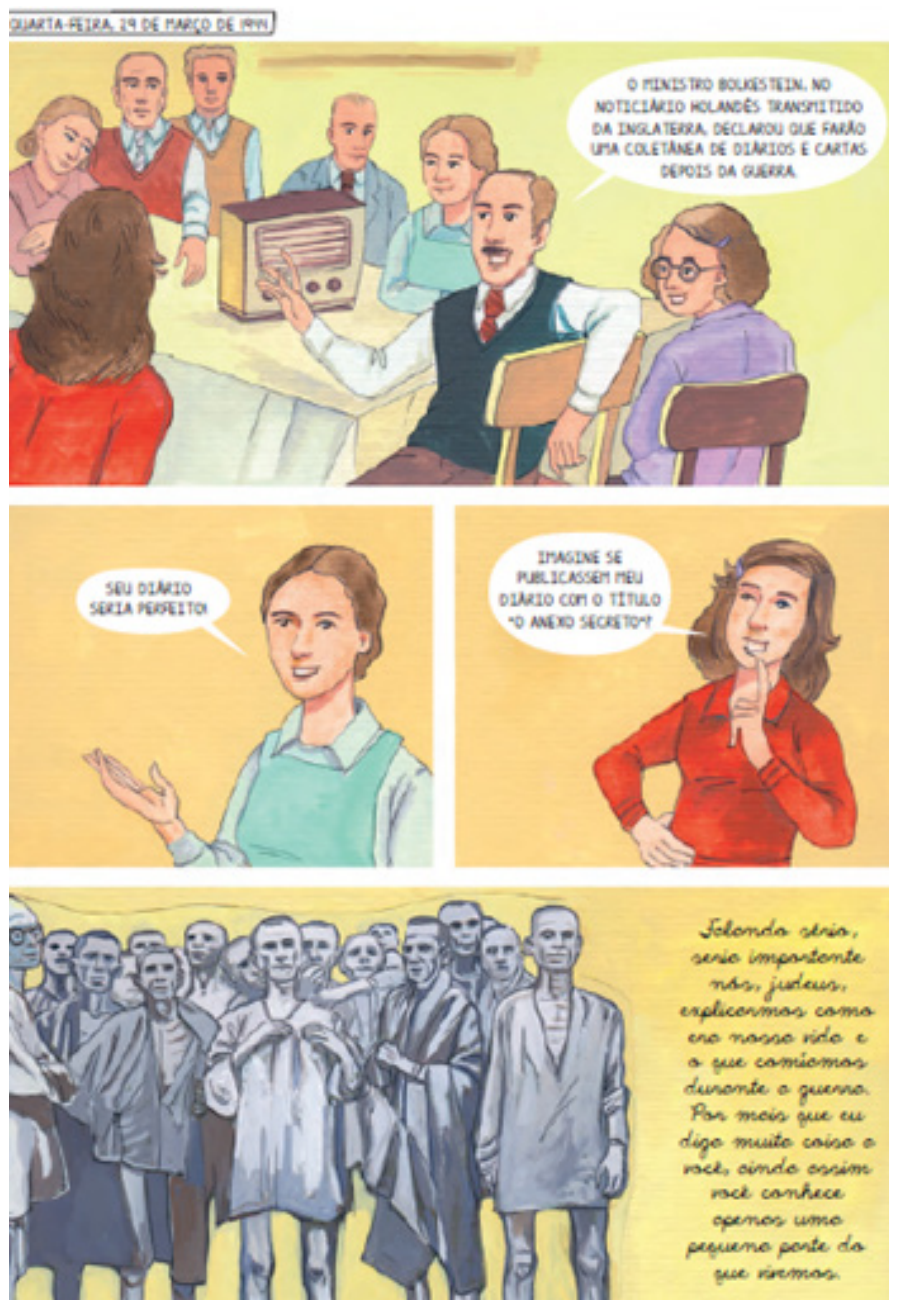

Fonte: Spinelli (2017, p. 63).

A Figura 1 descreve, inicialmente, o seguinte diálogo: "[...] o Ministro Bolkestein, no noticiário holandês transmitido da Inglaterra, declarou que farão uma coletânea de diários e cartas depois da guerra", diz o pai da Anne. 
"Querido diário..." A construção do conhecimento histórico por meio dos quadrinhos de Anne Frank

Em seguida, a mãe da adolescente responde: "Seu diário seria perfeito!" e Anne Frank fala: "Imagina se publicassem meu diário com o título 'O Anexo Secreto'?". A partir disso, a menina narra: "Falando sério, seria importante nós, judeus, explicarmos como era nossa vida e o que comíamos durante a guerra. Por mais que eu diga muita coisa a você, ainda assim você conhece apenas uma pequena parte do que vivemos" (SPINELLI, 2017, p. 63).

Para a compreensão do conceito de memória, amparamo-nos no pensamento de Halbwachs (2006, p. 69), ao defender que "[...] cada memória individual é um ponto de vista sobre a memória coletiva, que este ponto de vista muda segundo o lugar que ali [eu] ocupo e que esse mesmo lugar muda segundo as relações que [eu] mantenho com outros ambientes". Essa noção dialoga intimamente com nossa pesquisa, tendo em vista que Anne escreve sua memória individual em seu diário, mas é uma dentre várias perspectivas sobre a memória coletiva da guerra, respaldando-nos quanto à mobilização da fonte imagética (Figura 1) na proposta de ensino, considerando que a adolescente também ressalta a relevância dos judeus escreverem suas próprias versões desse contexto histórico.

Em seguida, identificamos os conceitos de cidadania e alteridade, 10 associando-os à ideia de consciência histórica de Rüsen (2011), na qual o autor argumenta que o conhecimento histórico possui aplicabilidade na vida prática e no cotidiano. Para tal, exercer a consciência histórica seria, de certo modo, praticar a cidadania e, consequentemente, viver melhor em sociedade, superando preconceitos e uma visão de mundo que demoniza o outro, a partir do pensamento histórico.

Sendo assim, a noção de cidadania, por exemplo, pode ser discernida na Figura 2, em que Anne Frank se expressa: "[...] fomos lembrados de que estamos escondidos, de que somos judeus, acorrentados, de que não temos direitos, mas, sim, milhares de deveres" (SPINELLI, 2017, p. 76). 


\section{Figura 2: Conceito de cidadania}

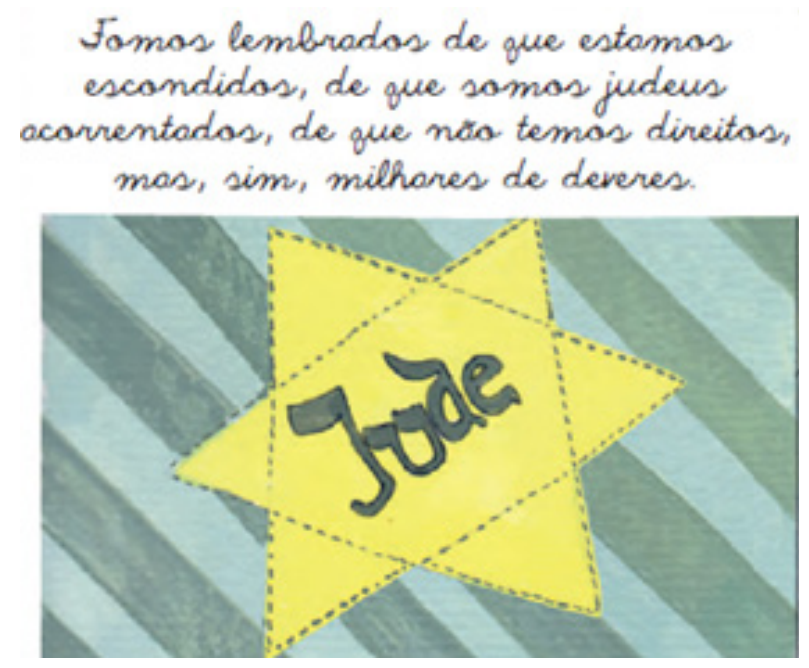

Fonte: Spinelli $(2017$, p. 76).

Já o conceito de alteridade é uma concepção elaborada com frequência durante toda a narrativa de Anne Frank, especialmente ao enfatizar a percepção do outro por meio das simbologias que os nazistas criam para diferenciá-los dos demais, como a estrela amarela costurada nas roupas. Nessa fonte imagética, Anne Frank se questiona: "[...] quem nos colocou nessa situação? Quem fez os judeus diferentes das outras pessoas? Quem permitiu que sofrêssemos tão terrivelmente até agora? Foi Deus quem nos fez assim e será Deus quem nos erguerá de novo" (SPINELLI, 2017, p. 77). 


\section{Figura 3: Conceito de alteridade}

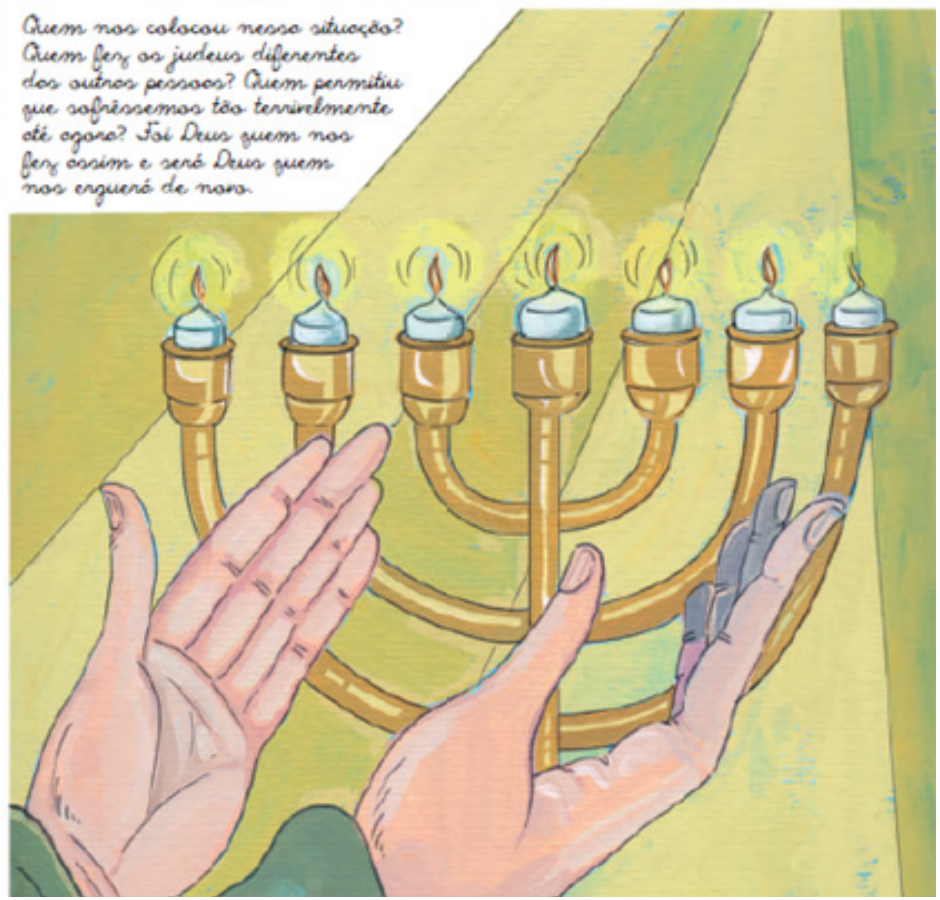

Fonte: Spinelli (2017, p. 77).

Por fim, selecionamos o conceito de fato histórico, dimensionando a sua historicidade, cuja produção, de acordo com Karnal e Tatsch (2009), ocorre a partir da documentação, no entendimento da fonte histórica como uma construção permanente, já que ela é oriunda de um diálogo entre o tempo presente e o que entendemos por vestígio histórico:

Se concluímos que não existe um fato histórico eterno, mas existe um fato que consideramos hoje um fato histórico, é fácil deduzir que o conceito de documento siga a mesma lógica. Fato e documento histórico demonstram nossa visão atual do passado, num diálogo entre a visão contemporânea e as fontes pretéritas (KARNAL; TATSCH, 2009, p. 13). 
Levando em consideração a perspectiva dos autores sobre o fato histórico, podemos relacioná-lo ao fragmento da adaptação em quadrinhos (Figura 4), em que Anne relata o que ela pretende escrever em seu diário:

\section{Figura 4: Conceito de fato histórico}

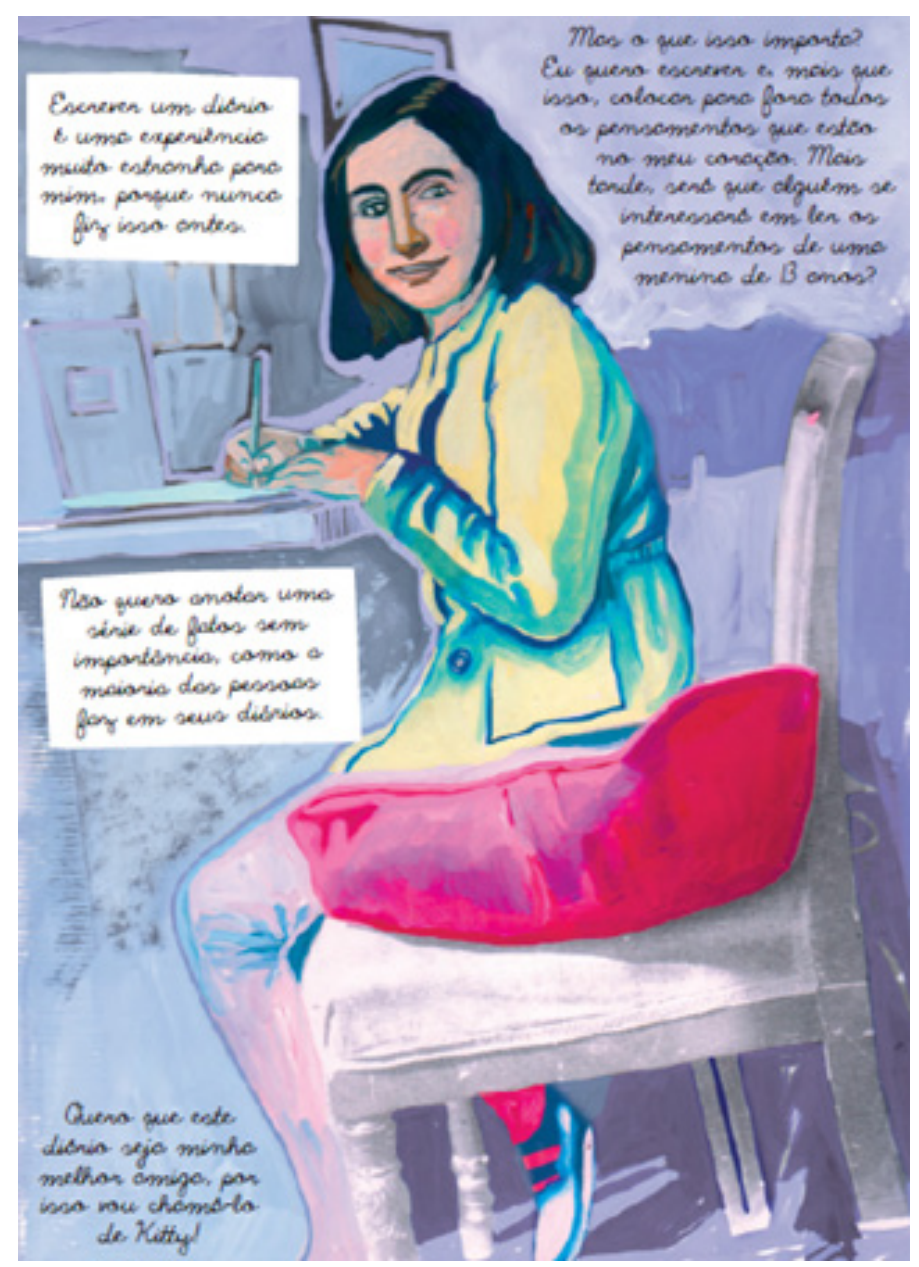

Fonte: Spinelli (2017, p. 11 ).

Escrever um diário é uma experiência muito estranha para mim, porque nunca fiz isso antes. Mas o que isso importa? Eu quero escrever e, mais que isso, colocar para fora todos os pensamentos 
que estão no meu coração. Mais tarde, será que alguém se interessará em ler os pensamentos de uma menina de 13 anos? Não quero anotar uma série de fatos sem importância, como a maioria das pessoas faz em seus diários. Quero que este diário seja minha melhor amiga, por isso vou chamá-lo de Kitty! (SPINELLI, 2017, p. $11)$.

Dessa forma, podemos abordar a noção de fato histórico que os alunos possuem e, consequentemente, a percepção da História, questionando se a frase "[...] não quero anotar uma série de fatos sem importância, como a maioria das pessoas faz em seus diários [...]" (SPINELLI, 2017, p. 1 1) representa esse campo do saber.

Essa indagação se torna pertinente a partir do momento em que há entendimento sobre a produção de um fato histórico muda de acordo com a perspectiva historiográfica que o pesquisador privilegia. Com as inovações historiográficas trazidas com a Nova História e a História Cultural, outros objetos e problemas passam a ser considerados na produção dos fatos históricos. Ou seja, indivíduos que antes eram excluídos passam a ser considerados sujeitos históricos, como é o caso da relatora do diário.

\section{A proposta de ensino: o questionário sociocultural}

Nossa proposta didática é composta por um questionário sociocultural e duas abordagens de ensino, a partir da obra de autoria de Anne Frank, adaptada em quadrinhos por Mirella Spinelli (2017), O diário de Anne Frank em Quadrinhos. A partir dessa fonte literária, buscamos favorecer a construção do conhecimento histórico dos estudantes.

Cabe ressaltar que esse projeto didático não pretende se apresentar em uma perspectiva engessada e inflexível. Além disso, é preciso considerar que não possuímos o perfil dos estudantes para desenvolver uma proposta direcionada a uma turma específica. Sendo assim, temos o intuito de produzir sugestões e recomendações dos usos de uma obra literária em sala de aula, baseadas no aporte teórico-metodológico adotado.

Levando em consideração que, para Bloch (2001 , p. 66), "[...] a educação da sensibilidade histórica nem sempre está sozinha em questão. Ocorre de, em uma linha dada, o conhecimento do presente ser diretamente ainda 
mais importante para a compreensão do passado", recomendamos que, de forma inicial, seja aplicado um questionário sociocultural, tendo em vista que é justamente por meio desse recurso que podemos nos aproximar, em alguma medida, dos conhecimentos prévios dos educandos, elemento essencial para que o processo de ensino-aprendizagem se guie pela realidade dos alunos e, consequentemente, crie sentido.

Para que possamos entender quais ideias pré-concebidas os alunos trazem para as aulas de História, devemos compreender que as fontes "[...] não falam senão quando sabemos interrogá-los" (BLOCH, 2001, p. 79), motivo pelo qual propomos o questionário semiestruturado, já que se torna essencial que essa seleção de questões tenha um caráter flexível e que possa incorporar novos tópicos que venham a aparecer durante sua aplicação. Como resultado dessa investigação, podemos rastrear vestígios que nos possibilitem conhecer além daquilo que o testemunho pretendia nos informar, extrapolando a documentação.

Dessa forma, a proposta do questionário se inicia com perguntas básicas sobre a identidade dos alunos: o nome, a idade, série, turma, sexo e a doutrina religiosa que professam. Também consideramos importante indagar como os educandos se classificam em relação à sua cor, segundo as categorias do Instituto Brasileiro de Geografia e Estatística (IBGE), podendo escolher entre branco, pardo, indígena, preto ou amarelo. Essas perguntas possuem o intuito de conhecer o perfil do aluno, dando destaque para a interrogação sobre a religiosidade, tendo em vista que essa informação se torna fundamental para a abordagem da História dos judeus, tema que permeia a narrativa da obra literária.

Se, por exemplo, a turma for composta por uma maioria de cristãos, podemos usar como questões problematizadoras da aula aquelas voltadas para o conhecimento dos estudantes sobre o judaísmo e as diferenças dessa religião para o cristianismo; se eles já passaram por alguma situação de intolerância religiosa; e, por fim, sondar se eles sabem por que os judeus e não outra religião/povo sofreram com as atrocidades do nazismo. São sugestões que podem contextualizar e introduzir o tema da aula, sendo importante para envolver os estudantes na temática proposta, criar um ambiente interativo e, também, é uma maneira de analisar, de forma oral, qual o conhecimento deles sobre o assunto de modo mais específico. 
Em sequência, sugerimos perguntar se os educandos possuem acesso à internet, pedindo para que, caso a resposta seja positiva, indiquem quantas horas por dia em média estão conectados. A próxima questão indaga qual o meio de comunicação eles utilizam para se manterem informados, tendo entre as opções: jornal escrito, jornal falado (TV ou rádio), internet, revistas e redes sociais, dando a opção para que, ao fim, os alunos especifiquem a preferência deles de mídia dentre essas categorias. Essa investigação busca entender os mecanismos que os estudantes usam para formar suas opiniões, validar suas percepções do tempo presente e se inteirar das notícias do mundo ao seu redor.

Nesse sentido, as questões a seguir mobilizam as percepções dos alunos acerca do ambiente escolar, buscando compreender se os adolescentes veem a instituição que estudam como fundamental para sua formação como sujeito e como se sentem em relação às disciplinas. Para tal, indagamos sobre a importância da escola para o seu futuro, apresentando como alternativas: a) se não possui importância; b) se tem pouca importância; c) se é importante, decisiva; ou d) se ele não sabe responder. A segunda pergunta se refere a quais matérias ele considera mais e menos importante e por quê.

Também consideramos essencial incluir questões que possuem como tema central a literatura, indagando se os educandos já tiveram contato com alguma história em quadrinhos antes e se leram algum livro, história em quadrinho, "fanfiction" ou mangá no último mês. A partir disso, podemos entender se eles conhecem ou não o formato das HQs e identificar os gêneros literários que os estudantes estão mais habituados a ler, e se gostam de ler.

Em seguida, as últimas cinco perguntas dizem respeito à compreensão de História que os estudantes possuem, especificamente: a) se é possível aprender História por meio da literatura; b) o motivo de se estudar História; e c) se existe alguma relação entre a disciplina e o cotidiano deles. Para finalizar, abordamos os conhecimentos prévios acerca do judaísmo e da História dos judeus, ao indagarmos o que eles sabem sobre ambos os temas. Temos a finalidade de explorar a visão de mundo desses alunos e ter a possibilidade de considerar essas preconcepções na sala de aula, partindo da realidade dos próprios adolescentes.

Após a aplicação do questionário semiestruturado, sugerimos que o docente dê uma aula introdutória sobre o contexto histórico, baseando-se nas 
problemáticas e questões que surgiram com a interpretação dos conhecimentos prévios dos estudantes, antes de dedicar-se ao uso das HQs nas aulas de História. Para trabalhar com esse recurso, recomendamos que o professor, se possível, dirija-se à biblioteca ou à sala de informática para que seja realizada uma leitura conjunta.

Como já ressaltamos, essa proposta não sugere uma prática única com as graphic novels; sendo assim, é interessante que o docente atue como mediador dessa leitura, fazendo pausas, determinando pequenas metas em que o educador e os alunos discutam o que aconteceu na narrativa até ali, por exemplo.

\section{A proposta de ensino: as atividades e os percursos de aprendizagem}

Baseamo-nos, para a primeira atividade, na dissertação de mestrado de Milian (2015), em que, após trabalhar com os estudantes sobre a obra literária de Lima Barreto, a autora elabora uma abordagem na qual analisa as narrativas dos estudantes por meio de um exercício empático das fontes literárias. Para tal, a partir da leitura conjunta de $\bigcirc$ diário de Anne Frank em Quadrinhos (SPINELLI, 2017), propomos um exercício com o seguinte enunciado:

1. Pensando no diário de Anne Frank e o que você estudou sobre a Segunda Guerra Mundial e os regimes totalitários, escolha uma das opções abaixo e imagine como seria viver nas seguintes situações descritas: política de Hitler;

Um cidadão ou soldado alemão que não concordava com a

- Uma mulher ou homem negro;

- Cigano/a;

- Pessoa com algum tipo de deficiência;

- $\quad$ Alguém cuja religião não é aceita pelo regime nazista (como as testemunhas de Jeová ou religiões de matrizes africanas);

- Pessoas de sexualidades diferentes das aceitas pelo regime nazista. 
A escolha de não colocar os judeus como uma das opções levou em consideração que, após a leitura da adaptação em quadrinhos sobre as vivências de Anne Frank, ao invés de se permitirem pensar a experiência na guerra que outras minorias tiveram, os educandos poderiam se amparar somente na perspectiva da adolescente por ser uma visão já conhecida, não explorando outras possibilidades.

Sendo assim, essa atividade é composta por situações em que os estudantes terão que dissertar e compreender a História como uma maneira de ver o mundo, ao pensarem historicamente, orientando-se no tempo e percebendo o passado como um fenômeno que possui continuidades e afeta o presente (LEE, 2016). Nesse sentido, uma das habilidades que essa prática pode proporcionar é o "olhar" do estudante para o passado sem interferências do tempo presente, uma tentativa de enxergar o contexto histórico por ele mesmo. Dessa maneira, construímos as seguintes indagações:

1. Como era o seu dia a dia?

2. O que mudou em seu cotidiano com os regimes totalitários?

3. $O$ que o personagem pensaria e sentiria ao ver os soldados nazistas na rua?

4. Em que tipo de casa e lugar da cidade morava? Como seria o seu bairro?

5. Como seriam as brincadeiras e seus vizinhos? Como seria a relação com seus vizinhos?

6. Como era a vida de sua família comparada com a de uma família rica?

7. Quais seriam os seus principais medos?

8. Quais seriam as principais preocupações de seus pais?

9. O que o personagem faria se soubesse que a guerra acabou?

10. O que a família da pessoa falaria/pediria para os líderes fascistas ou nazistas se os encontrassem?

11. Que outras perguntas você faria e responderia para que conhecêssemos mais o seu personagem?

12. Escolha um momento importante da vida do personagem e crie um desenho ou uma história em quadrinhos com diálogos sobre como ele se sente vivendo nesse período histórico. 
Podemos relacionar esse exercício diretamente ao conceito de empatia histórica de Peter Lee, tendo em vista que

[...] não se trata somente dos alunos saberem que os agentes ou grupos históricos tinham uma determinada perspectiva acerca do seu mundo; eles devem ser capazes de ver como é que essa perspectiva terá afetado determinadas ações em circunstâncias específicas (LEE, 2003, p. 20)

Em outras palavras, os estudantes devem entender o que esses personagens faziam, suas crenças, valores e seu modo de pensar sobre a realidade em que vivem, distanciando-se da sua visão de mundo que predomina o presente para desenvolver um raciocínio histórico sobre o passado. Além disso, Barca (2006, p. 95-96) defende que os alunos compreendam a História para além de uma grande e única narrativa do passado e que "[... num mundo de informação plural, será desejável que os alunos aprendam, de forma gradual, a comparar e a selecionar criteriosamente narrativas e fontes divergentes sobre um determinado passado".

Assim, propomos desenvolver, consequentemente, uma das competências narrativas sugeridas por Rüsen (201 1), em suas reflexões sobre o que deveria compor o material didático ideal para a construção da consciência histórica: a percepção histórica. Devemos considerar que, nessa abordagem de ensino, apresentamos um desafio para a compreensão interpretativa, considerando que o aluno elabora a competência perceptiva justamente ao se deparar com a estranheza e a diferença de outras temporalidades ao confrontá-la com suas vivências do presente. Em outras palavras, esse exercício evidencia as descontinuidades históricas e as mudanças que ocorreram em longo e curto prazo, além de apresentar uma perspectiva em que o mesmo fato histórico pode ser analisado de diferentes maneiras (RÜSEN, 2011 ).

Ao mobilizarmos uma representação da História como um processo, que pode ser entendido por múltiplos pontos de vista, estamos também potencializando o que Rüsen (2011) intitula de competência interpretativa, em que a consciência histórica percebe a História como um campo do saber cheio de significado para os estudantes.

Dessa maneira, elaboramos a segunda atividade com o intuito de compreender como os estudantes percebem os conceitos históricos e interpretam as fontes imagéticas, com a finalidade de mobilizar noções como literacia 
"Querido diário..." A construção do conhecimento histórico por meio dos quadrinhos de Anne Frank

histórica (LEE, 2016) e consciência histórica (RÜSEN, 2011). Nesse sentido, criamos seis questões que dialogam com os conceitos históricos e com as ilustrações de Mirella Spinelli. A primeira se apresenta da forma descrita a seguir:

1. A história de Anne Frank tem alguma relação com o momento presente? $\bigcirc$ que mudou e o que continuou desde a publicação do diário dela?

Essa pergunta intenciona mobilizar o conceito de tempo histórico, noção fundamental para este estudo, como argumenta Isabel Barca (2006), ao dissertar sobre o conceito de Peter Lee, definindo que é por meio da orientação temporal que os estudantes podem desenvolver a competência de "ler" e compreender o mundo pela História e, consequentemente, basear-se no passado para possibilitar novas perspectivas de futuro.

A segunda indagação estimula a concepção de tempo histórico, relacionando-a com o conceito de memória individual e coletiva:

2. O diário de Anne Frank mescla aspectos de seu cotidiano e elementos da Segunda Guerra Mundial, caracterizando o tempo histórico em que ela viveu. Sua história pode ser contada da mesma forma? Que aspectos poderiam ser destacados do período histórico em que você vive?

Sendo assim, ambas as questões podem ser interpretadas a partir da terceira competência narrativa definida por Rüsen (2011), em que o autor discute a orientação histórica, principalmente a segunda pergunta. Isso porque essa competência explicitada pelo autor tem como objetivo evidenciar o conhecimento histórico como uma forma de explicar o presente, definir as expectativas do futuro a partir do momento em que conecta a visão global e cotidiana com a vivência dos alunos, além de interagir com questões atuais e possuir a finalidade de que os estudantes formem uma opinião sobre a temática.

Em seguida, solicitamos que os educandos interpretassem um trecho da história em quadrinhos (Figura 1), no entanto devemos destacar que dividimos a fonte imagética em duas partes. $\bigcirc$ fragmento que compõe o primeiro segmento se refere ao conceito histórico de memória, enquanto o segundo elemento pede que analisem somente a imagem dos judeus, ou seja, optamos por retirar a fonte escrita de Anne Frank que acompanhava a ilustração com a finalidade de que a evidência imagética não fosse usada como mero acompanhamento do texto. Dessa forma, questionamos: 
3. Interprete o fragmento da $H Q$ (Figura 1 ) e responda as perguntas abaixo:

a) Sabendo que as fontes históricas são múltiplas lescrita, fotográfica, musical, pinturas, objetos etc.l, de que forma você preserva a sua memória? É importante registrar a memória do que acontece?

b) Por que os judeus foram retratados dessa forma na Imagem 2 ? O que você sente quando vê essa ilustração? Justifique.

c) Justifique o motivo de Anne Frank para considerar importante que os próprios judeus contem sua perspectiva da guerra. Qual a preocupação dela ao pensar nessa parte da história sendo contada por pessoas que não são judeus?

A exploração das imagens pode ser associada à ideia da aptidão narrativa da percepção histórica, formulada por Rüsen (201 1), pois, ao definir as características dessa capacidade, o autor ressalta a importância da apresentação da documentação histórica nesse processo, destacando que, apesar de as fontes imagéticas terem sido usadas somente com a função de ilustrar, atualmente, essa evidência histórica faz parte da experiência histórica interpretativa dos educandos.

O próximo conceito da História abordado no exercício quatro se refere à ideia de cidadania (Figura 2), em que pedimos para que os estudantes associem a imagem ao texto da graphic novel:

4. Observe a imagem (Figura 2) abaixo e responda:

a) Como a imagem se relaciona com o texto acima?

b) Existem pessoas hoje em dia que se sentem como Anne, sem direitos e com milhares de deveres? Justifique.

c) Se Anne se sentia sem direito na sociedade em que vivia, quais pessoas usufruíam desses direitos? Por quê?

A quinta questão mobiliza o conceito de alteridade, recomendando que os alunos percebam a conexão entre o aspecto textual e visual do fragmento da história em quadrinhos:

5. Relacione o texto e a imagem (Figura 3) a seguir:

a) O que você responderia às indagações de Anne Frank: "quem nos colocou nessa situação? Quem fez os judeus diferentes das outras pessoas? Quem permitiu que sofrêssemos tão terrivelmente até agora?" Justifique. 
"Querido diário..." A construção do conhecimento histórico por meio dos quadrinhos de Anne Frank

b) A ilustração desse trecho do diário transmite que tipo de sentimento ao leitor?

Essas noções de cidadania e alteridade podem ser conectadas a uma ideia de introduzir os educandos em um processo de construção da opinião histórica, característica da capacidade narrativa de orientação temporal de Rüsen (201 1). Ao refletir sobre a importância do debate a respeito dos juízos históricos, o autor propõe que sejam problematizados e usados como um meio de aprender sobre os fenômenos do passado. Devemos considerar que a ideia de consciência histórica se relaciona com a perspectiva de Peter Lee (2016), ao compreender que o conhecimento histórico pode ser utilizado na vida prática, sendo extremamente importante que assuntos do presente sejam discutidos em sala de aula.

Por fim, segue a última questão proposta para essa abordagem prática na sala de aula sobre os usos das HQs:

6. No início de seu diário, a adolescente escreve: "Não quero anotar uma série de fatos sem importância, como a maioria das pessoas faz em seus diários" (SPINELLI, 2017, p. 17).

a) Pensando na História, o que seriam fatos importantes e sem importância?

b) A frase que Anne Frank escreveu representa a História? Por quê? Frank?

c) Que fatos você destacaria na história em quadrinhos de Anne

Finalizamos a recomendação de prática na sala de aula com o conceito de fato histórico, tendo o intuito de perceber como, após a leitura dessa graphic novel, os educandos percebem a História e, consequentemente, as fontes históricas. Além disso, podemos interrogar se por meio do conhecimento histórico os estudantes estão criando sentido e orientando temporalmente as suas experiências como sujeitos históricos, de acordo com o conceito de consciência histórica, de Rüsen (2011).

Com isso, elaboramos essas recomendações de abordagens de ensino como uma maneira de apontar possibilidades para os estudantes pensarem historicamente através do uso de uma história em quadrinhos, $\bigcirc$ diário de Anne Frank em Quadrinhos (SPINELLI, 2017), entendendo essa fonte literária como uma forma de desenvolver o conhecimento histórico, valendo-se dos conceitos da História que podem ter outras aplicabilidades na vida prática dos 
estudantes. De modo específico, mobilizamos as noções de consciência histórica, literacia histórica e, por fim, a empatia histórica.

\section{Considerações finais}

Por se tratar de uma história em quadrinhos composta por elementos visuais e escritos, torna-se imprescindível uma análise prévia da obra literária e o mapeamento de conceitos históricos contidos na HQ. Esses aspectos nos respaldaram para a elaboração de dois exercícios que poderão desenvolver conceitos como a empatia histórica, literacia histórica e consciência histórica.

Ao longo do presente artigo, também identificamos conceitos da História que poderão ser construídos por meio do uso da história em quadrinhos na sala de aula, por exemplo: tempo histórico, memória, cidadania, alteridade e fato histórico. Devemos destacar que a operacionalização desse aparato teórico na escola possui grande relevância para o processo de ensino-aprendizagem dos estudantes, viabilizando que esse saber histórico possa ter aplicabilidade no cotidiano e não somente nas aulas de História.

Nesse sentido, construímos uma proposta de ensino constituída por um questionário sociocultural e duas atividades, ambas baseadas na perspectiva de Rüsen (201 1), tendo como intuito possibilitar a formação da consciência histórica pelos educandos, seja por meio dos conceitos históricos ou pelo desenvolvimento de um pensamento histórico pautado no aporte teórico de literacia histórica e empatia histórica (LEE, 2003; 2016).

Desse modo, buscamos mobilizar o conhecimento histórico como uma maneira de construir sentido e organizar, temporalmente, as experiências dos sujeitos, culminando numa História que tem por objetivo a formação da consciência histórica.

Ao analisarmos $O$ diário de Anne Frank em Quadrinhos (SPINELLI, 2017) e as suas possibilidades de usos no ensino de História, apresentamos os desafios dos docentes ao realizar abordagens de ensino que concebem as HQs como fonte histórica e recurso didático, principalmente quando não existem tantas pesquisas que estudam essa temática nas aulas de História.

Com apoio em Bloch (2001), entendemos que uma interpretação cuidadosa dos procedimentos usados para explorar a obra selecionada, possibilitou uma análise da história em quadrinho como documentação e como 
"Querido diário..." A construção do conhecimento histórico por meio dos quadrinhos de Anne Frank

recurso didático no Ensino de História. Assim, essa reflexão sobre os usos das graphic novels em sala de aula destacou a importância de mobilizarmos diferentes documentações no ambiente escolar e as múltiplas alternativas de percursos de aprendizagens que podem proporcionar uma nova forma de entender a História, principalmente quando os estudantes passam a compreender que essa disciplina não possui uma verdade única e podem, então, se reconhecer como sujeitos históricos diretamente afetados por esse passado, influenciando em suas perspectivas sobre o futuro.

Por fim, apostamos na potencialidade de desenvolver pesquisas na área do ensino de História e da realização de estratégias didáticas destinadas a favorecer a formação do pensamento histórico e da consciência histórica dos estudantes, como a focalizada neste artigo, a partir do uso de histórias em quadrinho.

\section{Notas}

1 Para esta busca, usamos as palavras-chaves: "Ensino de História", "Literatura", "histórias em quadrinhos", "hq", "graphic novel" e "Anne Frank".

242 A presente pesquisa deriva da monografia intitulada As histórias em quadrinhos no ensino de História: a construção do conhecimento histórico por meio do diário de Anne Frank, elaborada como trabalho de conclusão do curso de História da Universidade Federal do Espírito Santo, em 2020 .

3 Não obstante, a escolha dessa fonte literária também se deu pela proposta inicial de explorarmos tanto uma documentação literária escrita, quanto uma HQ na sala de aula com os estudantes. No entanto, esse projeto inicial de investigação não foi possível devido à pandemia da COVID-19, tornando necessário que fizéssemos ajustes em nossa metodologia.

4 Mirella Spinelli é graduada pela Universidade Federal de Minas Gerais em Belas Artes, pós-graduada em Arte Contemporânea na Pontifícia Universidade Católica de Minas Gerais e em História da Cultura e da Arte na Universidade Federal de Minas Gerais.

5 Programa criado em 1985, pelo Decreto n 91.542, dando início às avaliações pedagógicas periódicas para a qualificação do livro didático, com base em critérios sistemáticos. Contudo, a preocupação governamental com a questão do livro didático no Brasil pode ser visualizada desde a década de 1930, quando se produzem as primeiras políticas e programas dessa natureza (CAIMI, 2015).

6 A proposta de um questionário sociocultural se torna importante por possibilitar a análise do perfil dos estudantes e dos seus conhecimentos prévios sobre a História e a temática específica, interpretando sua visão de mundo e as demandas que eles podem trazer, mesmo que involuntariamente, ao responderem ao questionário.

7 A Nova História corresponde a uma corrente historiográfica francesa, de forma específica, a terceira geração dos Annales que, a partir do final dos anos 70, viabilizou a ampliação das 
fronteiras da História. Por meio desse novo olhar para os objetos de estudo da História, surge a História Cultural (BURKE, 1997).

8 Fanfictions são narrativas ficcionais escritas por fãs sobre determinados livros, filmes ou séries, por exemplo. Enquanto os mangás são histórias em quadrinhos produzidas no Japão ou feitas em um estilo japonês.

\section{Referências}

ALVES, Ronaldo Cardoso. Aprender história com sentido para a vida: consciência histórica em estudantes brasileiros e portugueses (São Paulo). 2011 . 322 f. Tese (Doutorado em Educação) - Programa de Pós-Graduação em Educação, Universidade de São Paulo, 2011.

AMARILHA, Marly. História em quadrinhos e literatura infantil: a paródia na formação do leitor. Revista Educação em Questão, Natal, v. 36, n. 22, set./dez. 2009.

AZEVEDO, Crislane Barbosa. Planejamento docente na aula de história: princípios e procedimentos teórico-metodológicos. Revista Metáfora Educacional, Salvador, n. 14, p. 3-28, jan./jun. 2013.

BARCA, Isabel. Literacia e consciência histórica. Educar em Revista, Curitiba, p. 93-1 12, 2006. (Número Especial).

$\mathrm{BLOCH}$, Marc. Apologia da história. Tradução André Telles. Rio de Janeiro: Zahar, 2001.

BRASIL, Ministério da Educação. PNLD. 27 ago. 2021 . Disponível em: http://portal.mec. gov.br/component/content/article?id=12391:pnld. Acesso em: 27 ago. 2021.

BURKE, Peter. A escola dos Annales (1929-1989): a revolução francesa da historiografia. Tradução Nino Odalia. São Paulo: Fundação Editora da UNESP, 1997.

CAIMI, Flávia Eloisa. As disciplinas escolares no contexto do PNLD: avanços, lacunas e desafios na avaliação do livro didático. Revista Educação Pública, Cuiabá, v. 24, n. 57 , p. 525-543, set./dez. 2015.

HALBSWACHS, Maurice. A memória coletiva. Tradução Beatriz Sidou. São Paulo: Centauro, 2006.

KARNAL, Leandro; TATSCH, Flavia Galli. In: PINSKY, Carla Bassanezi; LUCA, Tania Regina de (org.). O historiador e suas fontes. São Paulo: Contexto, 2009.

LEE, Peter. Educação histórica e museus. In: BARCA, Isabel (org.). Braga: Lusografe, 2003.

LEE, Peter. Em direção a um conceito de literacia histórica. Educar em Revista, Curitiba, p. 131-150, 2006. (Número Especial). 
"Querido diário..." A construção do conhecimento histórico por meio dos quadrinhos de Anne Frank

LEE, Peter. Literacia histórica e história formativa. Educar em Revista, Curitiba, n. 60, p. 107-146, 2016.

MILIAN, Vanessa Kiara Rodrigues. Literatura e ensino de história: a construção do conhecimento histórico em sala de aula a partir das crônicas de Lima Barreto. 2015. 151f. Dissertação (Mestrado em História Social) - Programa de Pós-Graduação em História Social, Universidade Estadual de Londrina, Londrina, 2015.

PEREIRA, Nilton Mullet; SEFFNER, Fernando. $\bigcirc$ que pode o ensino de história? Sobre o uso de fontes na sala de aula. Anos 90, Porto Alegre, v. 15, n. 28, p. $113-128,2008$.

RÜSEN, Jörn. O livro didático ideal. In: SCHMIDT, Maria Auxiliadora; BARCA, Isabel; MARTINS, Estevão de Rezende (org.). Jörn Rüsen e o ensino de história. Curitiba: Editora UFPR, 2011.

SCHMIDT, Maria Auxiliadora Moreira dos Santos. Jörn Rüsen e sua contribuição para a didática da História. Intelligere, Revista de História Intelectual, São Paulo, v. 3, n. 2, p. 60-76, set./dez. 2017 (Dossiê - Sentido e Relevância da História no Mundo Contemporâneo).

SILVA, Márcia Cabral da. Educação em escritas de si: o diário de Helena Morley 11893 1895). Revista Educação em Questão, Natal, v. 59, n. 60, abr./jun. 2021.

26 SPINELLI, Mirela. O Diário de Anne Frank em quadrinhos. Roteiro e ilustração de Mirella Spinelli. São Paulo: Nemo, 2017.

Bruna Mozini Subtil

Universidade Federal do Espírito Santo (Brasil)

Graduada em História

Membro do Grupo de Pesquisa Memórias, Narrativas e Histórias das/nas escolas: diálogos na formação de professores Orcid id: https:/ / orcid.org/0000-0002-7080-51 17

E-mail: bruna_mozini@hotmail.com 
Profa. Dra. Miriã Lúcia Luiz

Universidade Federal do Espírito Santo (Brasil) Membro do Núcleo Capixaba de Pesquisa em História da Educação (NUCAPHE) Coordenadora do Grupo de Pesquisa Memórias, Narrativas e Histórias das/nas escolas: diálogos na formação de professores Orcid id: http: / / orcid.org/0000-000 1-6825-1541

E-mail:miria.luiz@gmail.com

Recebido 17 maio 2021

Aceito 25 ago. 2021 